\title{
Iron-deficiency anemia among children in southwest Iran
}

\author{
Bijan Keikhaei, Khodamorad Zandian, Ali Ghasemi, and Ramin Tabibi
}

\begin{abstract}
Background. Iron deficiency is a major health problem worldwide and especially in developing countries. Irondeficiency anemia has adverse effects on the development of children.
\end{abstract}

Objective. The purpose of this study was to determine the prevalence of iron-deficiency anemia in children under 5 years of age in southwest Iran. The study also sought to investigate the association between socioeconomic, demographic, cultural, and nutritional factors and iron-deficiency anemia in the selected area.

Methods. A randomized, cross-sectional study was performed of children 6 to 59 months of age living in urban and rural areas of Ahwaz District in Khuzestan Province. At eight randomly selected health centers, the children's height (or length) and weight were measured, and information on length and weight at birth was obtained from growth charts. Blood samples were taken from 337 randomly selected children.

Results. The results showed that $43.9 \%$ of the children had anemia and $29.1 \%$ iron-deficiency anemia. The highest prevalence of iron-deficiency anemia was in the 12- to 24-month age group. In the urban areas, infants 6 to 11 months of age had the highest prevalence of irondeficiency anemia.

Conclusions. The high prevalence of iron-deficiency anemia among children in southwest Iran indicates a major nutrition and health problem.

Key words: Ahwaz, anemia, child, infant, Iran, iron

The authors are affiliated with the Research Center for Thalassemia and Hemoglobinopathy of Ahwaz, Iran.

Please direct queries to the corresponding author: Bijan Keikhaei, Research Center for Thalassemia and Hemoglobinopathy of Ahwaz, Ahwaz, Iran 61357-33119; e-mail: keikhaeib@yahoo.com.

\section{Introduction}

Iron deficiency is the most prevalent nutritional disorder in the world [1], and nearly 2 billion people suffer from anemia [2]. Iron deficiency is the most frequent cause of anemia [2-5]. In particular, iron-deficiency anemia has negative effects on infants, preschool children, and school-aged children [1]. Iron-deficiency anemia is related to a variety of developmental and behavioral measures. Iron-deficiency anemia is associated with a decrease of 10 to 15 points in the Bayley Scales of Infant Development, presumably due to a direct effect on the brain [6]. In the United States among adolescent girls, 9\% are iron deficient and 2\% have anemia [4]. The prevalence of anemia among children under 5 years of age is estimated to be about $20 \%$ in industrialized countries and $39 \%$ in nonindustrialized countries [1]. Iron-deficiency anemia is a major problem in Iran. According to the World Health Organization (WHO) classification, the prevalence of anemia in Iran is in the moderate category, which means that $10 \%$ to $39 \%$ of women and schoolgirls of reproductive age have hemoglobin concentrations below their reference values [7]. It is estimated that about $18 \%$ to $38 \%$ of Iranian children under 5 years of age are anemic [8].

\section{Materials and methods}

The study was designed as a randomized, crosssectional survey to determine the prevalence of irondeficiency anemia among children 6 to 59 months of age in Ahwaz District, the capital city of Khuzestan Province, located in southwest Iran. Primary health care in the rural areas is provided by Health Houses, each of which is capable of serving 1,500 people. Each Health House has at least one male and one female health worker (behvarz). The main function of a Health House is to provide primary health care services to its community. The urban Health Center is the official equivalent of the rural Health Center in the city and 
performs the same duties for approximately 12,000 people. All medical students in Iran have to spend part of their training in different stages of the primary health care fields.

The study was done in the urban and rural areas of Ahwaz, and two lower stages of the health care system (urban and rural Health Houses and Centers) were involved. Eight Health Houses and Centers were randomly selected, four in urban and four in rural areas. In the current study, the main variable was iron-deficiency anemia, which is a categorical variable. On the basis of previous similar studies, the prevalence of irondeficiency anemia was estimated to be around $30 \%$. For sample size calculation, power was determined as the study $=.80$ and alpha ( $)$ ) was equal to .05 (according to the previous studies); our estimation for the sample size was as follows:

$$
\begin{gathered}
N=Z^{2} P(1-P) / D^{2} \\
=(1.96)^{2}(0.3)(0.7) /(0.05)^{2}=322.69
\end{gathered}
$$

where $N$ is the estimated sample size, $Z$ equals the standard normal deviate at confidence level of more than $95 \%, P$ is the prevalence of iron-deficiency anemia, and $D$ is the absolute precision.

The participants were randomly selected from children 6 to 59 months of age. In the current study, the databases of the Health Centers were used to choose 40 children in each region by random selection.

Children who had a history of recent infection, liver disease, or ongoing high fever were excluded from the study because ferritin is an acute reactant-phase protein. The height (or length) and weight of the children were measured without shoes and adjusted to age by the Iranian children's standard Health Centers.

After the parents had been interviewed and anthropometric measurements had been completed, the child was taken to the laboratory of the urban Health Center or to the vaccination room in rural areas, and $4 \mathrm{~mL}$ of blood was collected by venipuncture. The nurse put $1 \mathrm{~mL}$ of blood in ethylenediaminetetraacetic acid (EDTA) for complete blood count test (CBC) and $3 \mathrm{ml}$ as clot sample for serum ferritin. The child's name, the date of sampling, the identification number, and the name of the Health Center (in urban or rural areas) were recorded on the blood tubes. In the laboratory, a complete blood count was performed on the uncoagulated blood by an enzyme-linked immunosorbent assay (ELISA) with a DIA plus kit.

\section{Results}

There were 337 participants: 165 (49\%) boys and 172 (51\%) girls. The percentages of boys and girls were $48.2 \%$ and $51.8 \%$ in the urban areas and $49.7 \%$ and $50.3 \%$ in the rural areas, respectively. The average age of the children was $31.1 \pm 16.05$ months. Most of the children were Arabian (79.8\%), and the rest belonged to different Persian (Fars) tribes. One hundred sixtyfour $(48.7 \%)$ were from urban areas and 173 (51.3\%) from rural areas. The majority of the families (63.5\%) had one or two children.

According to the survey results, the majority of mothers breastfed their babies for 13 to 24 months and fed them powdered milk for 7 to 12 months. In 11 families (3.3\%), the child was breastfed and given cow's milk at the same time (mean, $10.55 \pm 8.4$ months). Fifteen families (4.4\%) gave cow's milk to their children (mean, $11.13 \pm 6.19$ ). Only one family gave goat's milk to their child. Tea is a very popular drink in the south of Iran, especially in Khuzestan Province. One hundred thirty-one families (38.9\%) reported giving tea to their children (mean, $18.11 \pm 13.11$ months); $34.5 \%$ of families gave at least one cup of tea per day to their children, and $34 \%$ gave their children tea for 1 to 10 months.

Twenty-six children (7.7\%) were of low birthweight $(<2,500 \mathrm{~g})$, but the majority weighed more than $2,500 \mathrm{~g}$ at birth (mean, 3,162.4 $\pm 501.6 \mathrm{~g}$ ). The great majority of the children (92.3\%) were between 47 and $54 \mathrm{~cm}$ in length at birth (mean, $49.4 \pm 2.5 \mathrm{~cm}$ ).

Almost half of the children (46.1\%) were in the third centile of weight (mean, 12,428.3 $\pm 2,893.2 \mathrm{~g}$ ). More than one-third of the children (38.9\%) were in the third centile (mean, $88.3 \pm 12.3 \mathrm{~cm}$ ) of height (or length). According to the parents' statements, $12.2 \%$ of the children had a history of pica, and $12.8 \%$ of the mothers mentioned that their child had unusual crying.

Table 1 shows the complete blood count and serum

TABLE 1 . Laboratory results (mean \pm SD) for total investigated population according to sex and place of residence $(N=337)$

\begin{tabular}{|l|c|c|c|c|c|c|}
\hline Variable & $\mathrm{Hb}(\mathrm{mg} / \mathrm{dL})$ & $\mathrm{MCV}(\mathrm{fL})$ & $\mathrm{MCH}(\mathrm{pg})$ & $\mathrm{MCHC}(\%)$ & $\mathrm{RDW}$ & Ferritin $(\mu \mathrm{g} / \mathrm{L})$ \\
\hline Sex & & & & & \\
$\quad$ Female & $11.11 \pm 0.95$ & $77.83 \pm 6.86$ & $25.17 \pm 2.53$ & $32.30 \pm 0.82$ & $14.13 \pm 1.17$ & $17.17 \pm 24.14$ \\
$\quad$ Male & $11.07 \pm 1.07$ & $75.15 \pm 7.35$ & $24.32 \pm 2.82$ & $32.34 \pm 0.99$ & $14.61 \pm 1.15$ & $13.37 \pm 16.45$ \\
Residence & & & & & \\
$\quad$ Urban & $11.13 \pm 1.09$ & $76.92 \pm 6.62$ & $24.87 \pm 2.4$ & $32.32 \pm 0.88$ & $14.23 \pm 1.10$ & $12.8 \pm 10.17$ \\
$\quad$ Rural & $11.04 \pm 0.93$ & $76.14 \pm 7.74$ & $24.64 \pm 2.97$ & $32.32 \pm 0.93$ & $14.49 \pm 1.24$ & $17.68 \pm 27.11$ \\
\hline
\end{tabular}

$\mathrm{Hb}$, hemoglobin; MCV, mean corpuscular volume; $\mathrm{MCH}$, mean corpuscular hemoglobin; $\mathrm{MCHC}$, mean corpuscular hemoglobin concentration; RDW, red cell distribution width 
TABLE 2. Laboratory results (mean $\pm \mathrm{SD}$ ) for children with iron-deficiency anemia according to sex and place of residence $(N=98)$

\begin{tabular}{|l|c|c|c|c|c|c|}
\hline Variable & $\mathrm{Hb}(\mathrm{mg} / \mathrm{dL})$ & $\mathrm{MCV}(\mathrm{fL})$ & $\mathrm{MCH}(\mathrm{pg})$ & $\mathrm{MCHC}(\%)$ & $\mathrm{RDW}$ & Ferritin $(\mu \mathrm{g} / \mathrm{L})$ \\
\hline Sex & & & & & & \\
$\quad$ Female & $10.28 \pm 0.63$ & $73.40 \pm 7.58$ & $23.43 \pm 2.64$ & $31.88 \pm 0.81$ & $14.74 \pm 1.25$ & $6.14 \pm 2.70$ \\
$\quad$ Male & $10.20 \pm 0.71$ & $70.43 \pm 8.39$ & $22.48 \pm 3.10$ & $31.96 \pm 1.10$ & $15.30 \pm 1.28$ & $5.04 \pm 2.83$ \\
Residence & & & & & & \\
Urban & $10.20 \pm 0.71$ & $73.75 \pm 6.94$ & $23.60 \pm 2.28$ & $32.02 \pm 0.88$ & $14.63 \pm 1.17$ & $5.86 \pm 2.80$ \\
$\quad$ Rural & $10.26 \pm 0.65$ & $70.18 \pm 8.75$ & $22.35 \pm 3.29$ & $31.84 \pm 1.04$ & $15.39 \pm 1.31$ & $5.31 \pm 2.83$ \\
\hline
\end{tabular}

$\mathrm{Hb}$, hemoglobin; $\mathrm{MCV}$, mean corpuscular volume; $\mathrm{MCH}$, mean corpuscular hemoglobin; $\mathrm{MCHC}$, mean corpuscular hemoglobin concentration; RDW, red cell distribution width

ferritin results according to sex and urban versus rural residence. Girls had better blood-test results than boys, but there were no significant differences between urban and rural areas except for a higher level of serum ferritin in rural than in urban areas (27.11 vs. $10.17 \mu \mathrm{g} / \mathrm{L}$ ).

Table 2 shows the same hematologic indices for children with iron-deficiency anemia. Girls had slightly better findings than boys. The results in urban and rural areas were nearly the same, although urban areas had slightly higher values of mean corpuscular volume, mean corpuscular hemoglobin, mean corpuscular hemoglobin concentration, and serum ferritin.

Among the 337 participants, there were 98 cases (29.1\%) of iron-deficiency anemia (hemoglobin $<11 \mathrm{~g} / \mathrm{dL}$ and serum ferritin $<12 \mathrm{ng} / \mathrm{mL}$ ). Two hundred six (61.1\%) were iron deficient (serum ferritin $<12 \mathrm{ng} / \mathrm{mL}$ ), and 148 (43.9\%) had anemia (hemoglobin $<11 \mathrm{~g} / \mathrm{dL}$ ). There was no significant difference in the prevalence of anemia between the rural and the urban areas. The highest prevalence was in the 6- to 11-month age group (60.0\%); in the urban areas, the prevalence was $45.7 \%$ in this age group, and in the rural areas the prevalence was $27.3 \%$ in the 25 - to 36 -month age group (table 3 ).

The families in this study had one to nine children. The prevalence of anemia was highest in families with six or more children (47.1\%); in rural areas $35.3 \%$ of cases of anemia were in this group, whereas in urban areas only $11.8 \%$ of cases of anemia were in this group.

The majority of anemic children were from families in which the father's literacy level was low (primary school) or the mother was illiterate $(57 \%$ and $77.1 \%$ of cases, respectively). Anemia was most frequent in families of lower economic status. The prevalence of anemia was mostly seen in children weighing less than $2,500 \mathrm{~g}$ at birth $(53.8 \%)$.

On the other hand, in the urban areas, the prevalence of iron-deficiency anemia was highest in families in which the mother had a higher education degree (33.3\%); mothers with higher education and illiterate mothers had an equal chance of having a child with iron-deficiency anemia (33.3\%). However, in the rural areas, the prevalence of iron-deficiency anemia was highest in families in which the mother had a high school degree (44.4\%). The association between parents' education and iron-deficiency anemia was statistically significant.

The highest prevalence of iron-deficiency anemia was seen in families in which the father was unemployed (43.5\%). Families in which the mother was working in the private sector (non-governmental organizations) had the highest rate of iron-deficiency anemia among their children (50.1\%). The association between mother's job and iron-deficiency anemia in the children was statistically significant; mothers who worked in the private sector had a $0.063(6 \%)$ higher chance of having a child with iron-deficiency anemia.

There was no statistically significant relationship between iron-deficiency anemia in children and their parents' ethnicity.

TABLE 3. Distribution of pediatric anemia cases according to age group and place of residence

\begin{tabular}{|c|c|c|c|c|c|c|c|c|c|c|}
\hline \multirow{3}{*}{$\begin{array}{l}\text { Age } \\
\text { group } \\
\text { (mo) }\end{array}$} & \multicolumn{4}{|c|}{ All children } & \multicolumn{3}{|c|}{ Urban } & \multicolumn{3}{|c|}{ Rural } \\
\hline & \multirow[b]{2}{*}{$\begin{array}{l}\text { No. of } \\
\text { children }\end{array}$} & \multicolumn{2}{|c|}{ Anemia cases } & \multirow{2}{*}{$\begin{array}{l}\% \text { of chil- } \\
\text { dren in age } \\
\text { group with } \\
\text { anemia }\end{array}$} & \multicolumn{2}{|c|}{ Anemia cases } & \multirow{2}{*}{$\begin{array}{l}\% \text { of chil- } \\
\text { dren in age } \\
\text { group with } \\
\text { anemia }\end{array}$} & \multicolumn{2}{|c|}{ Anemia cases } & \multirow{2}{*}{$\begin{array}{l}\% \text { of chil- } \\
\text { dren in age } \\
\text { group with } \\
\text { anemia }\end{array}$} \\
\hline & & No. & $\begin{array}{c}\% \text { of all } \\
\text { cases }\end{array}$ & & No. & $\begin{array}{c}\% \text { of all } \\
\text { cases }\end{array}$ & & No. & $\begin{array}{c}\% \text { of all } \\
\text { cases }\end{array}$ & \\
\hline $6-11$ & 35 & 21 & 14.2 & 60.0 & 16 & 22.5 & 45.7 & 5 & 6.5 & 14.3 \\
\hline $12-24$ & 96 & 50 & 33.8 & 52.1 & 29 & 40.8 & 30.2 & 21 & 27.3 & 21.8 \\
\hline $25-36$ & 66 & 28 & 18.9 & 42.4 & 10 & 14.1 & 15.1 & 18 & 23.4 & 27.3 \\
\hline$\geq 36$ & 140 & 49 & 33.1 & 35.0 & 16 & 22.5 & 11.4 & 33 & 42.9 & 23.6 \\
\hline Total & 337 & 148 & 100.0 & 43.9 & 71 & 100.0 & 21.1 & 77 & 100.0 & 22.8 \\
\hline
\end{tabular}


The prevalence of low birthweight among the children was $7.7 \%$. The prevalence of iron-deficiency anemia was higher in low-birthweight children than in children of normal birthweight (34.6\% vs. $28.6 \%)$ and higher in rural low-birthweight children than in urban low-birthweight children ( $45.5 \%$ vs. $28.2 \%$ ), but these associations were not statistically significant. There were no statistically significant associations between iron-deficiency anemia and other anthropometric measurements, i.e., birth length, present weight, and present height (or length).

The prevalence of iron-deficiency anemia was highest among children 12 to 24 months of age in the total population and in the rural areas $(35.4 \%$ and $41.7 \%$, respectively). In the urban areas, the prevalence was highest among children under 1 year of age (40.7\%). There was no statistically significant association between the child's age and iron-deficiency anemia.

The prevalence of iron-deficiency anemia was highest among children of families who bottle-fed their children for 13 to 24 months in the total population and in the urban areas ( $24.3 \%$ and $22.7 \%$, respectively). In the rural areas, the prevalence was highest (57.1\%) in families who gave powdered milk to their children for 7 to 12 months.

In the total population, the highest prevalence of iron-deficiency anemia was seen in the families who gave tea to their children for 1 to 11 months (31.5\%) and those who gave their children two cups of tea daily $(32.1 \%)$.

\section{Discussion}

Iron-deficiency anemia is a widespread and preventable micronutrient deficiency. In primary health care, the priority is prevention rather than treatment [6].

Our results are similar to those of Kadivar et al. [9] in Fars Province and Karimi et al. [10] in Yazd Province in central Iran. In both studies there was no statistically significant relation between iron-deficiency anemia and sex. Similar studies in other parts of the world reached the same conclusion [11]. However, Domellöf et al. [12] found that there were substantial sex differences in hemoglobin concentration and other hematologic iron indices during infancy. They suggested several reasons for this; for instance, boys may be born with smaller iron resources because of their higher birthweight or may have more infections than girls. Domellöf et al. concluded that infant boys were at considerably higher risk of iron deficiency [12].

Young mothers were nearly twice as likely (odds ratio, 1.91) to have a child with iron-deficiency anemia than those in the baseline group of mothers 25 to 34 years of age [1]. In our sample of young mothers, $26.7 \%$ were illiterate, and $39.6 \%$ had a family income below the poverty line of $1,500,000$ rials (US $\$ 160$ ) per month.
Within this group of young mothers, $79.5 \%$ were of Arab ethnicity; 4 out of 9 of their children (44.4\%) had iron-deficiency anemia. Thus, it seems that younger mothers with frequent pregnancies were at greater risk of having children with iron-deficiency anemia.

Newborns of iron-deficient mothers have lower iron stores, with lower birthweights [2, 13], and a higher chance of preterm delivery $[14,15]$.

In this study, the highest prevalence of iron-deficiency anemia among children of young mothers was seen in children of 20 -year-old mothers (52\%). Twenty-year-old mothers living in urban areas had a greater chance of having a child with iron-deficiency anemia (87.5\%) than other mothers in the same age group (15 to 24 years old). Further analysis of data from young mothers surprisingly revealed that all 20 -year-old mothers in rural areas had three to five children, had family incomes below the poverty line (two-thirds of the fathers were unemployed), and were of Arab ethnicity.

Multiple risk factors appear to contribute to a higher prevalence of iron-deficiency anemia, and there was a surprising complex of risk factors: young mothers have multiple children without enough spacing between pregnancies due to factors such as lack of access to or use of proper contraceptives, illiteracy, low income, lack of hygiene, infections, and cultural factors (e.g., in some tribes families have more children or prefer male children). However, according to the UNICEF/ United Nations University/World Health Organization/ Micronutrient Initiative guidelines for iron-deficiency anemia [1], birth spacing helps women to recover from iron loss due to pregnancy.

Investigation of the parents' educational level and the prevalence of iron-deficiency anemia in Ahwaz indicated a paradox: that both parents who were illiterate, as well as those with higher education, had the highest percentage of children with iron-deficiency anemia. While our study, as well as others $[16,17]$, found an association between economic status and iron-deficiency anemia, evaluating household economic status poses substantial problems, and data related to assets, household income, and expenditure indicators are usually unreliable or unavailable in many developing countries [18].

In the current study, iron-deficiency anemia was most frequent in the families with lower income, a result in agreement with the WHO statement. Dietary limitations contribute to increase the rate of iron-deficiency anemia in Iran. For example, red meat, which is one of the main sources of heme iron, is expensive in Iran, as in many other developing countries. Bhargava et al. [17] point out that the high cost of products like red meat, fish, and poultry restricts their consumption by people of lower income groups in countries. Many Iranian families with low incomes may not be able to purchase adequate meat for their children's needs. 
In Ahwaz, iron-deficiency anemia was more prevalent among children with a history of preterm delivery. Prematurity is one of the main causes of neonatal death [19].

In our study, most children with iron-deficiency anemia were in the 12- to 24-month age group (second year of life), whereas in the urban areas infants 6 to 11 months of age (breastfed and formula-fed) had the highest prevalence of iron-deficiency anemia.

The relation between sex and iron-deficiency anemia was different in rural and urban areas. The prevalence of iron-deficiency anemia was lower in boys than in girls in the city $(25.3 \%$ vs. $30.6 \%)$ and higher in boys than in girls in the rural areas $(36.1 \%$ vs. $24.1 \%)$. There are several possible explanations for this difference: for instance, cultural beliefs such as that giving red meat to children will make them ill or cause parasitic diseases (especially worms). In addition, some tribes pay more attention to boys (especially in rural areas), so there may be some discrimination between boys and girls. Other cultural factors that may contribute to sexrelated differences in the prevalence of iron-deficiency anemia are education, ethnicity, and religion.

In this study, there was no significant difference between urban and rural areas in the relation of breastfeeding and iron-deficiency anemia, although the mean duration of breastfeeding was longer in children without than in children with iron-deficiency anemia (17.6 vs. 16.3 months, $p>.05)$. Our findings are consistent with those of Heidarnia et al. [20], who reported a mean breastfeeding duration of $17.4 \pm 6.3$ months.

In this study, families who gave tea to their children for 1 to 11 months and those who gave their children two cups of tea per day had the highest prevalence of children with iron-deficiency anemia.

\section{Conclusions}

The main cause of iron-deficiency anemia in children under 5 years of age, inappropriate nutrition, is affected by a series of socioeconomic and cultural factors. In this survey, the results of the fieldwork showed that in Ahwaz District of Khuzestan Province, there was a high prevalence of iron-deficiency anemia among infants and children. The prevalence is the same in urban and rural areas and in both sexes. Statistically it was proven that having a young mother and being in a family with six or more children were the best predictors for increased prevalence of iron-deficiency anemia among children under five. The mother has a vital role in feeding and in growth of the children (both physically and mentally). It was shown that there are several main risk factors for iron deficiency and anemia among children, such as parental illiteracy, low family income, and feeding cow's milk before 12 months of age.

Numerous studies have shown that pregnant women are at high risk for iron-deficiency anemia. During pregnancy and after delivery, women lose part of their body iron resources that should be recovered through dietary intake or iron supplementation. In this study, iron-deficiency anemia was more prevalent in children of families with young mothers than in children of families with older mothers.

We found that the failure to allow adequate time between pregnancies among young mothers because of poverty, cultural beliefs, lack of knowledge, or unavailability of or unwillingness to use contraceptives for birth control is a factor that has contributed to making this easily preventable nutritional disease a major health problem in southwest Iran.

Another important issue that emerged in this research is the higher prevalence of iron-deficiency anemia among younger children (12 to 24 months), who are a high-risk group for iron deficiency. Other studies [4] have also shown that children 6 to 24 months of age are at higher risk for iron-deficiency anemia than children in other age groups $[2,4,20]$. It is necessary to deal with this problem carefully, because any association between the economic situation of the investigated families and iron-deficiency anemia in the children was not statistically proven in this research (perhaps due to inadequate assessment of the family income through the survey); however, an association of iron-deficiency anemia in the children with other factors (e.g., the number of children) was confirmed. It is true that in developing countries, including Iran, there is some relation between family size and family economic situation; usually lower-income families have more members, and consequently the mother of the family, who is usually not educated or less educated, has to sacrifice quality of food for quantity. Instead of buying red meat, poultry, or fish, which are the main sources of protein and iron, the parents have to provide cheaper foods such as rice and bread to satisfy the children's hunger. 


\section{References}

1. Stoltzfus RJ, Dreyfuss ML. Guideline for the use of iron supplements to prevent and treat iron deficiency anemia. Washington (DC): ILSI Press, 1998.

2. Verster A. Guidelines for the control of iron deficiency in countries of the eastern Mediterranean, Middle East and North Africa. Alexandria, Egypt: World Health Organization, Regional Office for the Eastern Mediterranean 1996 (WHO-EM/NUT/177/E/G/11,96).

3. Murphy MF, Waisncoat J, Colvin BT. Microcytic anemia. In: Kumar P, Klark M. Clinical medicine, 5th ed. Edinburgh, UK: W. B. Saunders, 2002; 412-19.

4. Bertil G. Iron-deficiency anemia. In: Nelson textbook of paediatrics, 17th ed. Philadelphia, PA, USA: W. B. Saunders, 2004:1614-1615.

5. Hoffbrand AV, Pettit JE, Moss PAH. Essential haematology, 5th ed. Oxford, UK: Blackwell Science, 2001: 31-41.

6. Holst, M. Developmental and behavioral effects of iron deficiency anemia in infants. Nutr Today 1998;13:27-36.

7. Djazayery in collaboration with Rosannemarchesich (ESNA-FAO) Food and Agriculture Organization. Nutrition country profiles. January 23, Rome: FAO, 2002.

8. Bahrami M. Malnutrition and its effects on development in Iranian children. J Pediatr Dis 2004;14:149-56. (article in Persian)

9. Kadivar MR, Yarmohammadi H, Mirahmadizadeh AR, Vakili M, Karimi M. Prevalence of iron deficiency anaemia in 6 months to 5 years old children in Fars, Southern Iran. Med Sci Monit 2003;9:CR100-4.

10. Karimi M, Mirzaei M, Dehghani A. Prevalence of anaemia, iron deficiency and iron deficiency anaemia in 6-60 month old children in Yazd's rural area. International Pediatr 2004;19/No3:180-4.

11. Gunnarsson BS, Thorsdottir I, Palsson G. Iron status in 2-year-old Icelandic children and associations with dietary intake and growth. Eur J Clin Nutr 2004; 58:901-6.
12. Domellöf M, Lönnerdal B, Dewey KG, Cohen RJ, Rivera LL, Hernell O. Sex differences in iron status during infancy. Pediatrics 2002;110:545-52.

13. Freeman VE, Mulder ], van't Hof MA, Hoey HM, Gibney MJ. A longitudinal study of iron status in children at 12, 24 and 36 months. Public Health Nutr 1998;1:93-100.

14. Allen $\mathrm{H}$. Anemia and iron deficiency: Effects on pregnancy outcome. Am J Clin Nutr 2000;71(5 suppl):1280S-4S.

15. Karr MA, Mira M, Alperstein G, Labib S, Webster BH, Lammi AT, Beal P. Iron deficiency in Australian-born children of Arabic background in central Sydney. JAMA 2001;174:165-8.

16. Keskin Y, Moschonis G, Dimitriou M, Sur H, Kocaoglu B, Hayran O, Manios Y. Prevalence of iron deficiency among schoolchildren of different socio-economic status in urban Turkey. Eur J Clin Nutr 2005;59:64-71.

17. Bhargava A, Bouis HE, Scrimshaw NS. Dietary intake and socioeconomic factors are associated with the hemoglobin concentration of Bangladeshi women. J Nutr 2001;131:758-64.

18. Houweling TAJ, Kunst AE, Mackenbach JP. Measuring health inequality among children in developing countries: Does the choice of the indicator of economic status matter? International Journal for Equity in Health. 2003;2:8. Available at: http://www.equityhealthj.com. Accessed 31 August 2007.

19. Horbar JD, Badger GJ, Carpenter JH, Fanaroff AA, Kilpatrick S, LaCorte M, Phibbs R, Soll RF: Members of the Vermont Oxford Network. Trends in mortality for very low birth weight infants, 1991-1999. Pediatr 2002,110; 143-151.

20. Heidarnia A, Jalili Z, Dabiri S. The prevalence of iron deficiency anaemia in 1-5 years old children referring to Kerman medical care and health centers in 1998. Journal of the Kerman University of Medical Sciences 1999;6:214-21 (article in Persian). 